\title{
JOGOS EDUCACIONAIS DIGITAIS UTILIZADOS NO ENSINO DE MATEMÁTICA: UM MAPEAMENTO DAS PUBLICAÇÕES
}

\author{
Denise Ritter ${ }^{1}$; Ana Marli Bulegon²
}

\section{RESUMO}

Este trabalho apresenta os resultados de um mapeamento das produções científicas, realizado em 2021, de como os jogos educacionais digitais são utilizados no ensino de Matemática. As buscas foram realizadas no Catálogo de Teses e Dissertações, da CAPES, publicadas no período de 2010 a 2021. Após a leitura do título, do resumo e das palavras-chave foram analisados 15 trabalhos. A análise dessas produções possibilitou constatar que os jogos educacionais digitais são mais utilizados no Ensino Fundamental; no estudo das quatro operações matemáticas e de Geometria: para exercitar os conhecimentos dos estudantes após a explicação do professor. Nos trabalhos analisados, foram criados jogos e também utilizados os disponíveis nas plataformas digitais para computador. Com a popularização das tecnologias móveis, e seu uso na educação, acredita-se que haverá maior criação de jogos educacionais digitais, tanto por professores quanto pelos estudantes e seu uso ocorrerá em tempos e lugares diversos.

Palavras-chave: Mapeamento, Jogos educacionais digitais, Ensino de Matemática.

Eixo Temático: Educação, Cultura e Comunicação.

\section{INTRODUÇÃO}

Os jogos são recursos didáticos utilizados no ensino de Matemática em todos os níveis escolares há algum tempo. Depois do surgimento dos computadores e, mais especificamente do seu uso na educação, foram produzidos jogos digitais com finalidades educacionais. Na atualidade, com o distanciamento social, imposto pela

\footnotetext{
1 Doutoranda no Programa de Pós-Graduação em Ensino de Ciências e Matemática (PPGECIMAT) UFN. E-mail: deniseritter10@gmail.com.

2 Doutora em Informática na Educação, Professora do Programa de Pós-Graduação em Ensino de Ciências e Matemática (PPGECIMAT) - UFN. E-mail: anabulegon@ufn.edu.br.
} 
pandemia de COVID-19 o uso das tecnologias digitais potencializou o uso de jogos educacionais digitais no ensino.

Os jogos educacionais digitais são recursos que podem ser utilizados no ensino de Matemática para auxiliar no desenvolvimento de habilidades e na compreensão dos conteúdos(BOLLER; KAPP, 2018). Esse recurso pode ser utilizado em todos os níveis de ensino, de diversas formas e em diferentes momentos do processo de ensino e aprendizagem; tanto em ambiente de sala de aula quanto fora dela. Nessa perspectiva, o objetivo deste estudo é investigar como os jogos educacionais digitais são explorados no ensino de Matemática. Para atingir esse objetivo fez-se um levantamento de literatura, do tipo mapeamento, no Catálogo de Teses e Dissertações (CAPES), nas publicações de 2010 a 2021.

$\mathrm{Na}$ próxima seção são apresentadas algumas reflexões sobre as potencialidades dos jogos educacionais digitais. Na sequência é apresentada a análise e sistematização dos resultados, as considerações finais e referências utilizadas neste trabalho.

\section{JOGOS EDUCACIONAIS DIGITAIS}

Com o advento dos computadores e das tecnologias móveis, os jogos digitais passaram a ser recursos muito utilizados para o ensino em todas as áreas do conhecimento. Os jogos são recursos didáticos usados na educação desde a idade infantil até a adulta. Conforme Boller e Kapp (2018, p. 14)

Jogo é uma atividade que possui: um objetivo; um desafio (ou desafios); regras que definem como o objetivo deverá ser alcançado; interatividade, seja com outros jogadores ou com o próprio ambiente o jogo (ou com ambos); e mecanismos de feedback, que ofereçam pistas claras sobre quão bem (ou mal) o jogador está se saindo.

De acordo com Mattar (2010, p. 8) os jogos digitais podem ser ferramentas educacionais, pois eles

respeitam os diferentes estilos de aprendizagem e com isso permitem uma maior aproximação entre conteúdo e alunos, principalmente por poder atender às principais características de aprendizagem dos nativos digitais, além de fazer parte do seu dia a dia e do seu mundo.

Nessa perspectiva, Tiziam (2018) aponta que os jogos educacionais digitais podem motivar os estudantes, despertando seu interesse para o conteúdo que está 
sendo estudado, melhorando, dessa forma, seu engajamento nas atividades propostas.

Borin (2004, p. 8) salienta que a atividade de jogar, se bem orientada, tem importante papel no ensino de Matemática, pois auxilia no desenvolvimento de habilidades como por exemplo, organização, atenção e concentração, e ainda, auxilia na resolução de problemas.

\section{METODOLOGIA}

Essa pesquisa realizou-se por meio de um estudo de natureza qualitativa, de caráter bibliográfico do tipo mapeamento, que conforme Fiorentini et al. (2016, p. 18) trata-se de "[...] um processo sistemático de levantamento e descrição de informações acerca das pesquisas produzidas sobre um campo específico de estudo, abrangendo um determinado espaço (lugar) e período de tempo". Nesse estudo, o objetivo é investigar como os jogos educacionais digitais são explorados no ensino de Matemática.

Para atingir esse objetivo, inicialmente as buscas foram feitas no Catálogo de Teses e Dissertações, da CAPES, nas publicações de 2010 a 2021, e fizeram uso dos termos "jogo AND educacional AND digital AND Matemática". Essa base de dados foi escolhida para este mapeamento, pois tencionamos, em um primeiro momento, investigar as pesquisas, acerca dessa temática, desenvolvidas nos níveis dos cursos de mestrado e doutorado.

\section{RESULTADOS - ANÁLISE E SISTEMATIZAÇÃO}

Num primeiro momento, a partir do uso das palavras-chave, foram encontrados 22 trabalhos. Posteriormente, foram adotados critérios de exclusão como: trabalhos duplicados e trabalhos que não tratam sobre o uso de jogos educacionais digitais no ensino de Matemática. Nessa etapa, foram excluídos 7 trabalhos, restando 15 para serem analisados.

Para análise desses trabalhos, além do objetivo de verificar como os jogos educacionais digitais são explorados no ensino de Matemática, foram elencadas mais algumas questões: Qual o nível de ensino em que os jogos educacionais digitais são 
mais utilizados no ensino da Matemática? Os jogos são para computador ou celular? Quais os conteúdos de Matemática são mais abordados? Em qual momento pedagógico os jogos educacionais digitais são utilizados?

No Quadro 1 apresentamos uma síntese das Dissertações e Teses analisados, com destaque para o título, tipo de trabalho (dissertação ou tese), autor - ano, objetivo geral e o nome do jogo utilizado no respectivo trabalho.

Quadro 1 - Dissertações e Teses analisadas

\begin{tabular}{|c|c|c|c|}
\hline $\begin{array}{l}\text { Tipo de trabalho - } \\
\text { Título }\end{array}$ & $\begin{array}{l}\text { Autor } \\
\text { Ano }\end{array}$ & Objetivo geral & \begin{tabular}{|l} 
Jogo \\
utilizado
\end{tabular} \\
\hline $\begin{array}{l}\text { Dissertação } \\
\text { Metacognição: um } \\
\text { estudo exploratório com } \\
\text { o game educacional } \\
\text { Fazendinha Matemática } \\
\text { aplicado em estudantes } \\
\text { do } \\
\text { Fundamental. }\end{array}$ & $\begin{array}{l}\text { Márcio } \\
\text { Antonio } \\
\text { Sales } \\
\text { Venancio } \\
(2020)\end{array}$ & $\begin{array}{l}\text { Analisar as manifestações do } \\
\text { pensamento metacognitivo de } \\
\text { estudantes, jogadores assíduos, } \\
\text { eventuais e não jogadores, quando } \\
\text { submetidos a uma situação de } \\
\text { aprendizagem Matemática mediada } \\
\text { por um game educacional digital. }\end{array}$ & $\begin{array}{l}\text { Fazendinha } \\
\text { Matemática }\end{array}$ \\
\hline $\begin{array}{l}\text { Dissertação } \\
\text { Modelagem de jogo } \\
\text { educacional digital para } \\
\text { o ensino e a } \\
\text { aprendizagem de } \\
\text { Matemática Básica na } \\
\text { Educação Profissional e } \\
\text { Tecnológica. }\end{array}$ & $\begin{array}{l}\text { Daniel } \\
\text { Lisboa de } \\
\text { Menezes } \\
(2020)\end{array}$ & $\begin{array}{l}\text { Analisar um modelo de ensino e } \\
\text { aprendizagem baseado em jogo } \\
\text { educacional digital como recurso } \\
\text { metodológico para a aprendizagem } \\
\text { de Matemática básica na Educação } \\
\text { Profissional e Tecnológica. }\end{array}$ & $\begin{array}{l}\text { Mundo de } \\
\text { João }\end{array}$ \\
\hline $\begin{array}{l}\text { Dissertação } \\
\text { Aprendizagem de } \\
\text { Grandezas em um } \\
\text { ambiente lúdico: as } \\
\text { aventuras do Edu em } \\
\text { um Jogo Educacional } \\
\text { Digital. }\end{array}$ & $\begin{array}{l}\text { Marcus } \\
\text { Antonio } \\
\text { Vieira } \\
\text { Dalvi } \\
(2020)\end{array}$ & $\begin{array}{l}\text { Desenvolver e analisar o uso de um } \\
\text { jogo educacional digital no processo } \\
\text { educativo de Grandezas e de } \\
\text { Proporcionalidade. }\end{array}$ & $\begin{array}{l}\text { As } \\
\text { Aventuras } \\
\text { de Edu }\end{array}$ \\
\hline $\begin{array}{lr}\text { Dissertação - } & \text { O jogo } \\
\text { digital Quiz PG } & \text { para o } \\
\text { aprendizado } & \text { de } \\
\text { Progressão } & \\
\text { Geométrica. } & \end{array}$ & $\begin{array}{l}\text { Williane } \\
\text { Costa } \\
\text { Ferreira } \\
(2020\end{array}$ & $\begin{array}{l}\text { Analisar quais resultados o jogo } \\
\text { digital Quiz PG pode produzir a partir } \\
\text { da sua utilização didática para o } \\
\text { aprendizado do conteúdo de P.G. }\end{array}$ & Quiz PG \\
\hline $\begin{array}{l}\text { Tese - Proposta de um } \\
\text { jogo digital como } \\
\text { instrumento de apoio a }\end{array}$ & $\begin{array}{l}\text { Helio } \\
\text { Fernando } \\
\text { Gomes }\end{array}$ & $\begin{array}{l}\text { Desenvolver e validar uma } \\
\text { ferramenta tecnológica digital- } \\
\text { educacional, baseada nas teorias de }\end{array}$ & $\begin{array}{l}\text { Jurandir e } \\
\text { os segredos } \\
\text { da }\end{array}$ \\
\hline
\end{tabular}




\begin{tabular}{|c|c|c|c|}
\hline $\begin{array}{l}\text { EDUCAÇÃO, SAÚD: } \\
\text { E TECNOLOCIA } \\
26 \text { A } 28 \text { DE OUTUBRO DE } 2021\end{array}$ & & & $\begin{array}{l}\text { ISSN: } 2316-9745 \\
\text { TRABALHO COMPLETO }\end{array}$ \\
\hline $\begin{array}{ll}\text { Avaliação } & \text { Formativa } \\
\text { Contínua sobre } \quad 0 \\
\text { conteúdo de }\end{array}$ & $\begin{array}{l}\text { Maziviero } \\
(2019)\end{array}$ & $\begin{array}{l}\text { game design, cuja finalidade é o } \\
\text { apoio ao diagnóstico das dificuldades } \\
\text { e facilidades dos alunos em conteúdo } \\
\text { de Matemática, em particular ao } \\
\text { ensino de Funções, de maneira a } \\
\text { consolidar de modo mais efetivo o } \\
\text { uso do processo de avaliação } \\
\text { formativa. }\end{array}$ & Matemática \\
\hline $\begin{array}{lr}\text { Dissertação } & \text { A } \\
\text { tecnologia educacional } \\
\text { no ensino da } \\
\text { Geometria: } \\
\text { digitais. }\end{array}$ & $\begin{array}{l}\text { André Luiz } \\
\text { Tiziam } \\
(2018)\end{array}$ & $\begin{array}{l}\text { Analisar as vantagens da utilização } \\
\text { da tecnologia dos jogos digitais no } \\
\text { ensino da Geometria. }\end{array}$ & $\begin{array}{l}\text { Geometrian } \\
\text { do }\end{array}$ \\
\hline $\begin{array}{l}\text { Dissertação - Material } \\
\text { Dourado Digital: } \\
\text { software educativo para } \\
\text { o ensino de Operações } \\
\text { Fundamentais } \\
\text { Matemáticas. }\end{array}$ & $\begin{array}{l}\text { Allessio da } \\
\text { Silva } \\
(2017)\end{array}$ & $\begin{array}{l}\text { Desenvolver e aplicar um jogo com a } \\
\text { representação do Material Dourado } \\
\text { numa versão digital, tendo a } \\
\text { finalidade de abordar os conceitos } \\
\text { básicos envolvidos nas operações } \\
\text { matemáticas de subtração e adição } \\
\text { para alunos do Ensino Fundamental } \\
\text { l. }\end{array}$ & GolDigiMat \\
\hline $\begin{array}{l}\text { Dissertação - A } \\
\text { aprendizagem do } \\
\text { conceito científico de } \\
\text { Fração por alunos com } \\
\text { Deficiência Intelectual: } \\
\text { os resultados de uma } \\
\text { intervenção. }\end{array}$ & $\begin{array}{l}\text { Sastria de } \\
\text { Paula } \\
\text { Rodrigues } \\
(2017)\end{array}$ & $\begin{array}{l}\text { Planejar e implementar uma } \\
\text { intervenção pedagógica, tendo, como } \\
\text { sujeitos-foco, alunos com deficiência } \\
\text { intelectual, utilizando, como recurso } \\
\text { pedagógico, um jogo educacional } \\
\text { digital de Matemática, procurando } \\
\text { avaliar se o uso dessa tecnologia, } \\
\text { mediado pela professora na } \\
\text { coletividade, contribuiu para a } \\
\text { aprendizagem dos conceitos } \\
\text { científicos do referido campo } \\
\text { curricular. }\end{array}$ & Scratch \\
\hline $\begin{array}{l}\text { Dissertação - Diálogos e } \\
\text { Tecnologia no Ensino } \\
\text { de Matemática: um } \\
\text { olhar sobre cotidiano e } \\
\text { diversidade. }\end{array}$ & $\begin{array}{l}\text { Luiz } \\
\text { Marcelo } \\
\text { André } \\
\text { Fontes } \\
\text { (2017) }\end{array}$ & $\begin{array}{l}\text { Produzir um jogo digital, na } \\
\text { perspectiva da diversidade e } \\
\text { inclusão, e realizar estudos visando } \\
\text { identificar quais contribuições essa } \\
\text { tecnologia, que aborda conteúdos de } \\
\text { Matemática do Ensino Fundamental, } \\
\text { pode trazer para situações de ensino } \\
\text { na diversidade. }\end{array}$ & DUM 2 \\
\hline $\begin{array}{lr}\text { Dissertação } & - \text { Estudo } \\
\text { sobre as } \\
\text { potencialidades do Jogo } \\
\text { Digital Minecraft para o }\end{array}$ & $\begin{array}{l}\text { Hudson } \\
\text { William da } \\
\text { Silva } \\
(2017)\end{array}$ & $\begin{array}{l}\text { Analisar as potencialidades do jogo } \\
\text { digital Minecraft para o ensino de } \\
\text { proporcionalidade e de tópicos de } \\
\text { Geometria Plana e Espacial em uma }\end{array}$ & Minecraft \\
\hline
\end{tabular}




\begin{tabular}{|c|c|c|c|}
\hline $\begin{array}{l}\text { EDUCAÇÃO, SAÚDE } \\
\text { E TECNOLLOGIA } \\
{ }_{26} \text { A } 28 \text { DE OUTUBRO DE } 2021\end{array}$ & & & $\begin{array}{r}\text { ISSN: } 2316-9745 \\
\text { TRABALHO COMPLETO }\end{array}$ \\
\hline $\begin{array}{lr}\text { ensino } & \text { de } \\
\text { Proporcionalidade } & \mathrm{e} \\
\text { tópicos de Geometria. }\end{array}$ & & situação real de aprendizado. & \\
\hline $\begin{array}{lr}\text { Dissertação } & - \\
\text { EduCoelho: uma } \\
\text { plataforma } \\
\text { Alfabetização } \\
\text { Financeira estimulando } \\
\text { a reflexão } \\
\text { comportamental. }\end{array}$ & $\begin{array}{l}\text { Eduardo } \\
\text { Wartchow } \\
(2017)\end{array}$ & $\begin{array}{l}\text { Concepção de uma plataforma } \\
\text { educacional de Educação Financeira, } \\
\text { a partir da identificação de princípios } \\
\text { norteadores para sua elaboração, } \\
\text { buscando com seu desenvolvimento, } \\
\text { produzir aprendizagens e reflexões } \\
\text { que gerem significado. }\end{array}$ & EduCoelho \\
\hline $\begin{array}{l}\text { Dissertação - Jogo para } \\
\text { o auxílio ao aprendizado } \\
\text { de Matemática na } \\
\text { Educação Especial. }\end{array}$ & $\begin{array}{l}\text { Murilo } \\
\text { Rodrigues } \\
\text { da Rocha } \\
(2016)\end{array}$ & $\begin{array}{l}\text { Desenvolver um software no formato } \\
\text { de jogo educacional no formato } \\
\text { digital para dispositivos móveis } \\
\text { (tablets e smartphones), visando o } \\
\text { auxílio pedagógico ao processo de } \\
\text { aprendizagem da disciplina de } \\
\text { Matemática na modalidade especial } \\
\text { de ensino, com foco nas séries } \\
\text { iniciais do Ensino Fundamental. }\end{array}$ & $\begin{array}{l}\text { Jogo do } \\
\text { aprendizado }\end{array}$ \\
\hline $\begin{array}{l}\text { Dissertação - O jogo em } \\
\text { jogo: a contribuição dos } \\
\text { games no processo de } \\
\text { aprendizagem dos } \\
\text { estudantes do Ensino } \\
\text { Fundamental. }\end{array}$ & $\begin{array}{l}\text { Carla } \\
\text { Alexandre } \\
\text { Barboza } \\
\text { de Sousa } \\
(2015)\end{array}$ & $\begin{array}{l}\text { Investigar como a utilização de jogos } \\
\text { digitais contribui com o processo de } \\
\text { aprendizagem de estudantes do } \\
\text { Ensino Fundamental. }\end{array}$ & Combus \\
\hline $\begin{array}{l}\text { Dissertação - Análise } \\
\text { com TRI da utilização } \\
\text { de jogo digital no ensino } \\
\text { de Matemática do } \\
\text { Ensino Fundamental II. }\end{array}$ & $\begin{array}{l}\text { Ingrid } \\
\text { Bahia } \\
\text { Chaves } \\
\text { (2013) }\end{array}$ & $\begin{array}{l}\text { Analisar via TRI a utilização de um } \\
\text { jogo digital com conteúdo de } \\
\text { Matemática para o Ensino } \\
\text { Fundamental II a partir de um modelo } \\
\text { que melhor se encaixe nas variadas } \\
\text { situações através dos dados obtidos } \\
\text { pelos testes digitais (JogoMat) e } \\
\text { escrito nos graus de dificuldade fácil, } \\
\text { médio e difícil. }\end{array}$ & JogoMat \\
\hline $\begin{array}{l}\text { Dissertação - Os } \\
\text { videogames como } \\
\text { recurso de ensino- } \\
\text { aprendizagem: uma } \\
\text { experiência nas aulas } \\
\text { de Matemática do } \\
\text { Ensino Fundamental na } \\
\text { rede pública. }\end{array}$ & $\begin{array}{l}\text { Cláudia } \\
\text { Maria } \\
\text { Lopes de } \\
\text { Avelar } \\
\text { Burihan } \\
\text { (2009) }\end{array}$ & $\begin{array}{l}\text { Analisar a contribuição dos } \\
\text { videogames como recurso didático e } \\
\text { estímulo ao processo de } \\
\text { aprendizagem. }\end{array}$ & The Sims 2 \\
\hline
\end{tabular}

Fonte: elaborado pelas autoras com base nos dados coletados. 
A análise das publicações (Quadro 1) permite dizer que foram utilizados diversos jogos educacionais digitais com vistas a contribuir na aprendizagem dos conceitos de Matemática. Em relação aos dispositivos utilizados para ter acesso aos jogos educacionais digitais percebeu-se forte predominância (13) pela utilização de computadores, enquanto que o acesso por dispositivos móveis (celular, tablets) foi menor (3). Ressalta-se que em um dos trabalhos analisados o jogo proposto poderia ser acessado tanto por dispositivo móvel como pelo computador.

Também verificou-se em que nível de ensino as publicações analisadas realizaram intervenções utilizando jogos educacionais digitais, como pode ser observado no Gráfico 1.

Gráfico 1 - Nível de ensino em que os jogos educacionais digitais foram utilizados

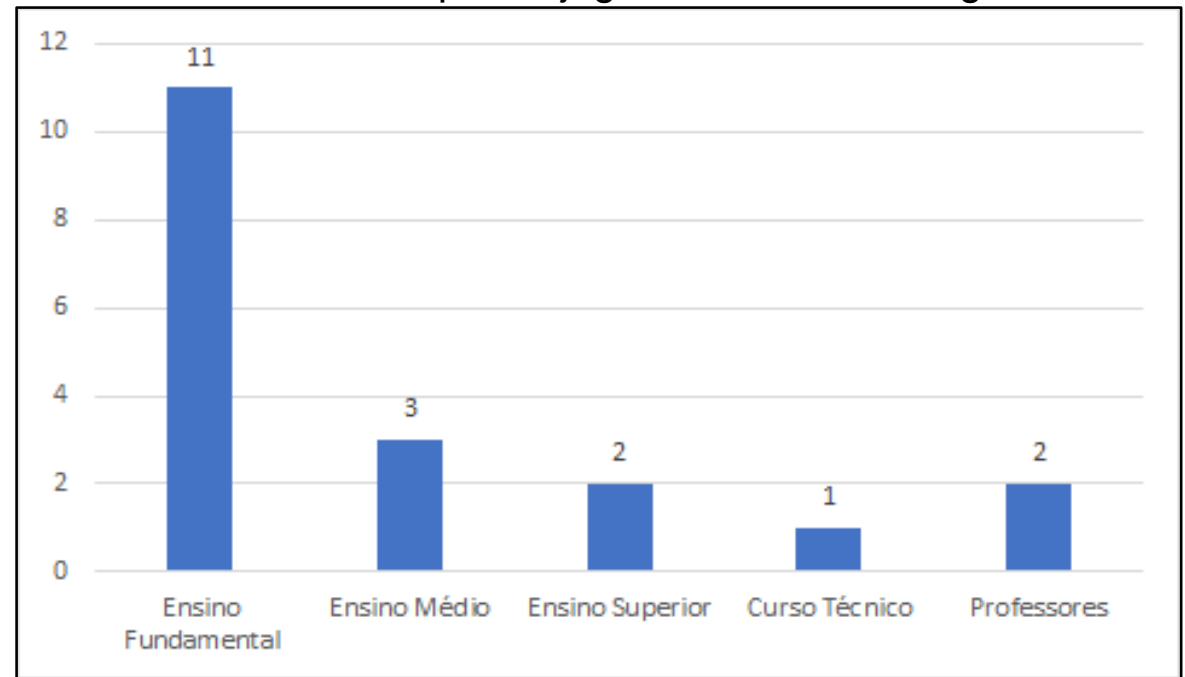

Fonte: elaborado pelas autoras com base nos dados coletados.

Percebe-se forte predominância pela utilização dos jogos educacionais digitais no Ensino Fundamental, visto que 11 publicações utilizaram esse recurso nesse nível de ensino, apesar de que quatro dos trabalhos analisados utilizaram os jogos educacionais digitais em mais de um nível de ensino.

Os conteúdos matemáticos contemplados nos jogos educacionais digitais (Gráfico 2) referem-se a diversas áreas, com maior ênfase para Geometria e operações matemáticas básicas.

Gráfico 2 - Conteúdos matemáticos dos jogos educacionais digitais analisados 

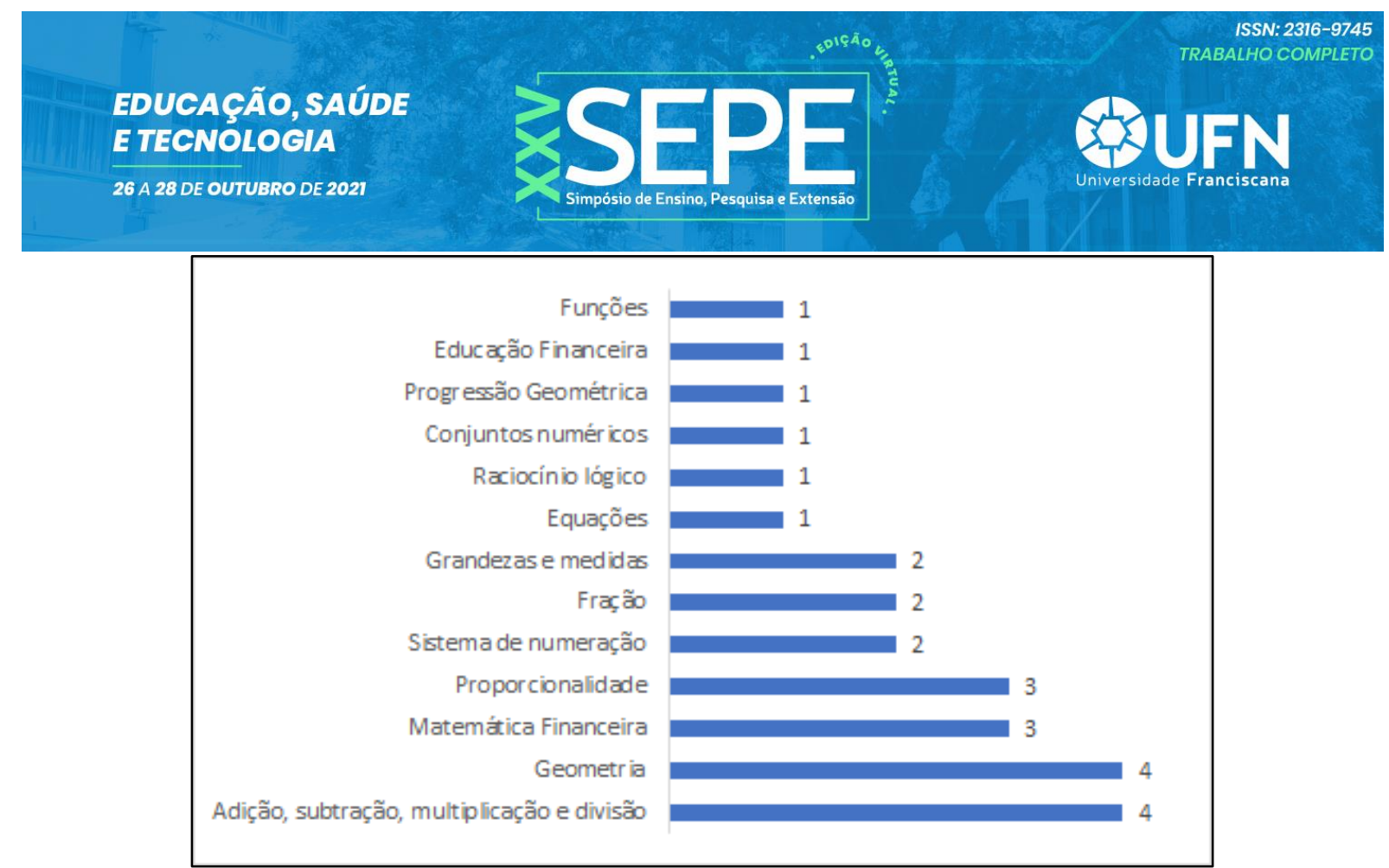

Fonte: elaborado pela autora com base nos dados coletados.

Apesar de alguns jogos contemplarem conceitos que são abordados no Ensino Médio, como Funções, verificou-se que a predominância dos conceitos refere-se à Matemática básica, trabalhados no ensino Fundamental, o que também permite o uso deles em diferentes momentos pedagógicos do Ensino Médio e Superior.

No Gráfico 3, é apresentada a análise do momento pedagógico (revisar, introduzir, exercitar, avaliar) em que os jogos educacionais digitais foram utilizados.

Gráfico 3 - Momento pedagógico em que os jogos educacionais digitais foram utilizados

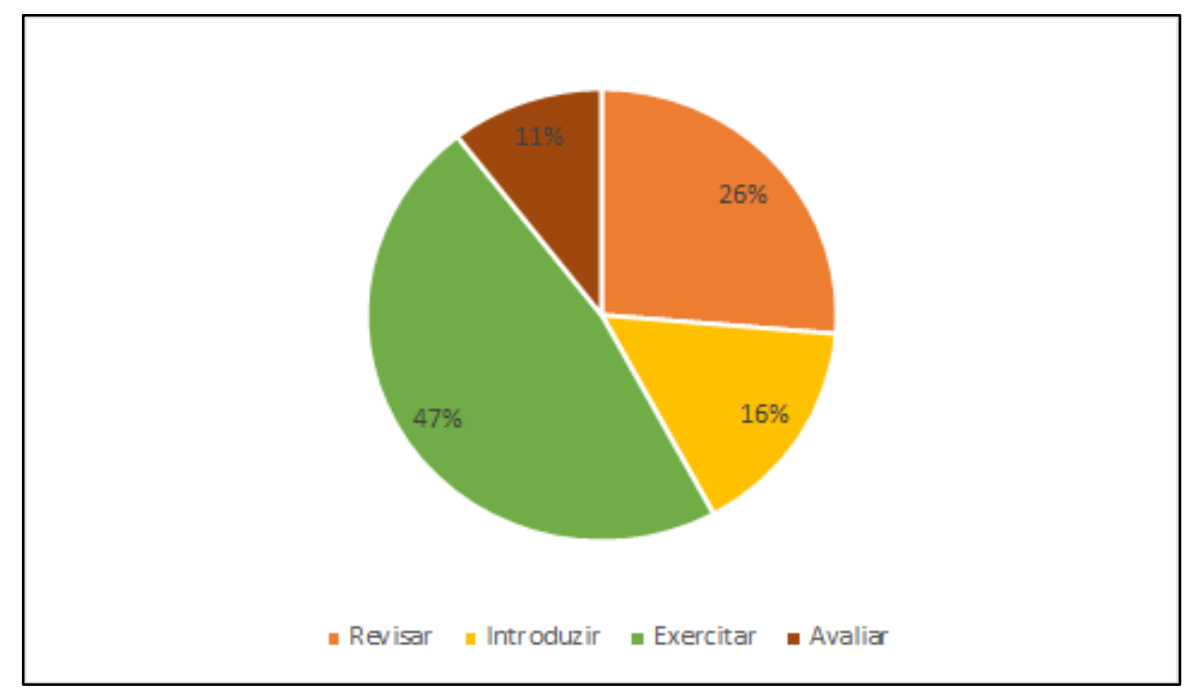

Fonte: elaborado pelas autoras com base nos dados coletados. 
Percebe-se que os jogos educacionais digitais são mais utilizados para exercitar o conteúdo (47\%), após a explicação do conteúdo pelo professor, como forma de os estudantes aplicarem seus conhecimentos; para revisar (26\%) os conhecimentos, estudados em aula ou os conhecimentos prévios que são necessários para aprender o conteúdo; para introduzir (16\%) o conteúdo e para avaliar (11\%) o que os estudantes aprenderam.

Verificou-se que são utilizados jogos educacionais digitais diversos nas aulas de Matemática, e que os professores têm se empenhado em projetos que visam sua crriação. Isso corrobora com os escritos de KlopFer, Osterweil e Salen (2009) que reforçam a necessidade de avançar na produção de jogos educacionais digitais, pois atualmente são poucos os modelos para guiar seu desenvolvimento e os existentes não contemplam esses tipos de jogos de modo eficaz.

\section{CONCLUSÃO}

O objetivo desse trabalho era investigar como os jogos educacionais digitais são explorados no ensino de Matemática. A análise realizada possibilitou perceber que os jogos educacionais digitais são mais utilizados com o intuito de os estudantes exercitarem o conteúdo estudado. Outro aspecto relevante, se refere a predominância pela utilização desse recurso no Ensino Fundamental no estudo das quatro operações (adição, subtração, multiplicação e divisão) e no conteúdo de Geometria.

Percebeu-se a preocupação dos docentes em criar seus próprios jogos educacionais digitais e também na utilização dos que já estão disponíveis em plataformas digitais com ênfase nos computadores. Com a popularização das tecnologias móveis acredita-se que serão produzidos e utilizados mais jogos educacionais digitais, tanto para serem usados com computadores quanto com smartphones e tablets, visto que esse tipo de tecnologia possibilita o acesso do estudante ao jogo em diferentes momentos e espaços, inclusive fora da sala de aula.

\section{AGRADECIMENTOS}

O presente trabalho foi realizado com apoio da Coordenação de Aperfeiçoamento de Pessoal de Nível Superior - Brasil (CAPES) - Código de Financiamento 001. 


\section{REFERÊNCIAS}

BOLLER, S.; KAPP, K. Jogar para Aprender: tudo o que você precisa saber sobre o design de jogos de aprendizagem eficazes. São Paulo: DVS Editora, 2018.

BORIN, J. Jogos e resolução de problemas: uma estratégia para as aulas de Matemática. São Paulo: IME-USP, 2004.

BURIHAN, C. M. L. de A. Os videogames como recursos de ensinoaprendizagem: uma experiência nas aulas de Matemática do Ensino Fundamental da rede pública. 2009. 112f. Dissertação (Mestrado em Tecnologias da Inteligência e Design Digital) - Pontifícia Universidade Católica de São Paulo, São Paulo, 2009.

\section{CHAVES, I. B. Análise com TRI da utilização de Jogo Digital no ensino de}

Matemática do Ensino Fundamental II. 2013. 91f. Dissertação (Mestrado em Engenharia da Informação) - Universidade Federal do ABC, Santo André, 2013.

DALVI, M. A. V. Aprendizagem de Grandezas em um ambiente lúdico: as aventuras do EDU em um Jogo Educacional Digital. 2020. 94f. Dissertação (Mestrado em Educação em Ciências e Matemática) - Instituto Federal do Espírito Santo, Campus Vitória, Vitória, 2020.

FERREIRA, W. C. O Jogo Digital Quiz PG para o aprendizado de Progressão Geométrica. 2020. 163f. Dissertação (Mestrado em Ensino de Ciências e Matemática) - Universidade Federal de Alagoas, Maceió, 2020.

FIORENTINI, D.; GRANDO, R. C.; MISKULIN, R. G. S.; CRECCI, V. M.; LIMA, R. C. R. de; COSTA, M. C. O professor que ensina Matemática como campo de estudo: concepção do projeto de pesquisa. In: FIORENTINI, D.; PASSOS, C. L. B.; LIMA, R. C. R. de. Mapeamento da pesquisa acadêmica brasileira sobre o professor que ensina Matemática: período 2001 - 2012. São Paulo: FE/UNICAMP, 2016, p. 17-41. 
FONTES, L. M. A. Diálogos e Tecnologia no Ensino de Matemática: um olhar sobre cotidiano e diversidade. 2017. 123f. Dissertação (Mestrado Profissional em Diversidade e Inclusão) - Universidade Federal Fluminense, Niterói, 2017.

KLOPFER, E.; OSTERWELL, S.; SALEN, K. Moving learning games forward: obstacle, opportunities e openness. Education Arcade. MIT, 2009. Disponível em: $<$ http://education.mit.edu/papers/MovingLearningGamesForward_EdArca de.pdf\#page=5\&zoom=auto,0,395> Acesso em 20 ago. 2021.

MAZIVIERO, H. F. G. Proposta de um Jogo Digital como instrumento de apoio a Avaliação Formativa Contínua sobre o conteúdo de Funções. 2019. 103f. Tese (Doutorado em Educação para a Ciência) - Faculdade de Ciências da Universidade Estadual Paulista, Bauru, 2019.

MATTAR, J. Games em educação: como os nativos digitais aprende. São Paulo: Pearson Prentice Hall, 2010.

MENEZES, D. L. de. Modelagem de Jogo Educacional Digital para o Ensino e a Aprendizagem de Matemática Básica na Educação Profissional e Tecnológica. 2020. 120f. Dissertação (Mestrado Profissional em Educação Profissional e Tecnológica) - Instituto Federal da Paraíba, João Pessoa, 2020.

ROCHA, M. R. da. Jogo para o auxílio ao aprendizado de Matemática na Educação Especial. 2016. 133f. Dissertação (Mestrado em Ciências) - Universidade Tecnológica Federal do Paraná, Curitiba, 2016.

RODRIGUES, S. de P. A aprendizagem do conceito científico de Fração por alunos com Deficiência Intelectual: os resultados de uma intervenção. 2017. 168p. Dissertação (Mestrado em Educação) - Universidade Federal do Pampa, Jaguarão, 2017 
SILVA, A. da. Material Dourado Digital: software educativo para o ensino de Operações Fundamentais Matemáticas. 2017. 15f. Dissertação (Mestrado Profissional em Ensino de Ciências e Matemática) - Universidade Estadual da Paraíba, Campina Grande, 2017.

SILVA, H. W. da. Estudo sobre as potencialidades do Jogo Digital Minecraft para o ensino de Proporcionalidade e tópicos de Geometria. 2017. 113f. Dissertação (Mestrado em Educação Matemática) - Pontifícia Universidade Católica de São Paulo, São Paulo, 2017.

SOUSA, C. A. B. de. O jogo em jogo: a contribuição dos Games no processo de aprendizagem dos estudantes do Ensino Fundamental. 2015. 155f. Dissertação (Mestrado em Educação Matemática e Tecnológica) - Universidade Federal de Pernambuco, Recife, 2015.

TIZIAM, A. L. A tecnologia educacional no ensino da Geometria: Jogos Digitais. 2018. 101f. Dissertação (Mestrado em Ensino Científico e Tecnológico) - Universidade Regional Integrada do Alto Uruguai e das Missões, Santo Ângelo, 2018.

VENANCIO, M. A. S. Metacognição: um estudo exploratório com o game educacional Fazendinha Matemática aplicado em estudantes do Ensino Fundamental. 2020. 114f. Dissertação (Mestrado em Ensino) - Universidade Estadual do Sudoeste da Bahia, Bahia, 2020.

WARTCHOW, E. EduCoelho: uma plataforma de Alfabetização Financeira estimulando a reflexão comportamental. 2017. 108f. Dissertação (Mestrado em Ensino de Ciências e Matemática) - Universidade de Caxias do Sul, Caxias do Sul, 2017. 